\title{
Formação para Cidadania e Controle Social via Educação a Distância
}

\author{
Cassyra Lucia Correa BarrosVuolo', Cristiano Maciel $^{2}$, Alexandre Martins dos \\ Anjos $^{2}$, Ana Paula Kuhn², Taciana Mirna Sambrano ${ }^{2}$, Claudia Oneida Rouiller ${ }^{1}$ \\ ${ }^{1}$ Tribunal de Contas do Estado de Mato Grosso \\ Cuiabá - MT - Brazil \\ ${ }^{2}$ Universidade Federal de Mato Grosso (UFMT) \\ Cuiabá - MT - Brazil \\ \{cassyra, claudia\}@tce.mt.gov.br, \{crismac, dinteralexandre\}@gmail.com, \\ \{profapaulaunemat, tacianamirna\} @hotmail.com
}

\begin{abstract}
Brazilian councils for the management of public policies are spaces for the exercise of citizenship, which requires preparation. This paper presents the results of the union between different public government institutions to offer an online course on Citizenship and Social Control. This initiative of education for transparency was intended to integrate the government and the civil society, as well as to foster transparency and enable society to perform the social control. The scientific publicization of the lessons learned in this initiative, which reached about 700 citizens by means of a Learning Management System, can spur new actions and reflections in this area.
\end{abstract}

Resumo. O exercício da cidadania requer preparo, o qual, na estrutura brasileira, tem um espaço privilegiado nos conselhos de gestão das políticas públicas. Neste sentido, este artigo apresenta os resultados da união entre diferentes instituições governamentais públicas para realização de um curso de "Cidadania e Controle Social" via Educação a Distância. Tal iniciativa de educação para transparência serve para aproximação e integração do governo e da sociedade civil, bem como de estímulo a transparência e capacitação da sociedade para realização do controle social. A divulgação científica das lições apreendidas nesta iniciativa, que atingiu cerca de 700 cidadãos, via ambiente virtual de aprendizagem, pode fomentar novas ações e reflexões nesta área.

\section{Introdução}

Para que possamos ter uma democracia participativa, é necessário a participação dos cidadãos na vida pública (MACIEL, GARCIA, 2007). Segundo Nerling (2017), a comunidade, a cidadania, a participação, a transparência e o controle permeiam as diversas etapas do ciclo de gestão de políticas públicas. Todavia, o exercício da cidadania requer preparo, o qual, tem um espaço privilegiado na estrutura brasileira dos conselhos de gestão das políticas públicas (NERLING, 2017).

No que se refere ao controle social, é uma forma de compartilhamento do poder de decisão entre o Estado e sociedade em relação às políticas. É um instrumento da democracia e da cidadania. E pode ser realizado tanto no momento da implantação de políticas públicas quanto no momento de fiscalização (KUHN et al., 2017). Para Kuhn 
et al. (2017), o controle interno, por sua vez, tem por finalidade o acompanhamento das funções das atividades dos órgãos subordinados à administração, observando os princípios constitucionais estabelecidos no âmbito da gestão pública. Por certo que os conselhos não são os únicos instrumentos de democratização e controle social sobre a gestão dos recursos públicos, mas são os que possuem na sua composição, de forma paritária, representantes do governo e da sociedade e têm, por natureza, o dever de propor e avaliar os resultados das políticas públicas.

É nessa conjuntura que ocorre a articulação entre o Tribunal de Contas de Mato Grosso (TCE-MT) com os conselhos de políticas públicas, foco desta pesquisa. O TCEMT, enquanto o órgão responsável pela fiscalização dos resultados da gestão pública, com capilaridade sobre os dados relacionados às políticas públicas para elevar a efetividade e a transparência de suas decisões, pode empoderar os conselhos para a realização de controle social (GIRATA et al., 2013; OLIVEIRA; MACIEL, 2013). Somente com informações e conhecimento de suas funções na democracia participativa serão possíveis o acompanhamento e a fiscalização do poder público pelos conselhos de políticas públicas.

Face ao exposto, o presente artigo apresenta os resultados da união de esforços entre diferentes instituições governamentais públicas por meio da adoção da Educação a Distância como ferramenta pedagógica de aproximação, integração e capacitação da sociedade para realização do controle social. Esta experiência exitosa teve início em 2012 com esforços conjuntos de órgãos governamentais. Na ocasião, o Tribunal de Contas do Estado de Mato Grosso (TCE-MT) tomou a decisão de firmar parceria com a Universidade Federal do Estado de Mato Grosso (UFMT), por intermédio da Fundação de Apoio e Desenvolvimento da UFMT (Fundação Uniselva), para realizar o curso de extensão intitulado "Cidadania e Controle Social" via Educação a Distância (EaD), reconhecendo a universidade pública como lócus de conhecimento tecnológico e formação para a cidadania política (VUOLO; MACIEL, dos ANJOS, 2017).

Segundo Maciel et al. (2016), sugere-se na "área de Educação, entre outros, o desenvolvimento de soluções para desenvolver a educação para a transparência e o incentivo ao uso de dados abertos governamentais na forma gráfica como meio de atrair a atenção e facilitar o entendimento dos dados pelos cidadãos de modo a elevar e melhorar o nível de participação democrática no país.". Os autores sugerem um conjunto de ações a serem realizadas, também para a área de "Educação Digital". A educação para transparência é algo que se faz necessário e premente. Na literatura, em especial no Brasil, são escassos os trabalhos nesta área, todavia percebem-se iniciativas neste contexto educativo como a dos autores Monsalve, Werneck e Leite (2013), em um estudo de transparência especificamente com jogos digitais na área de Pedagogia.

No curso resultante da parceria supracitada, o objetivo foi permitir a inclusão cidadã nos processos participativos de gestão a partir da disponibilização de informações e de conhecimentos que favorecessem o empoderamento social e a interface entre os controles externo e social. O curso foi realizado no Ambiente Virtual de Aprendizagem (ANJOS, 2014) Moodle. A análise do processo e dos resultados da iniciativa mediada pelas tecnologias contribui para o debate sobre a relevância da educação coorporativa permitindo ampliar as reflexões sobre como esta pode ser oferecida para toda a sociedade.

A proposta do curso trouxe também para análise e compartilhamento a 
contribuição possível e efetiva da união de esforços entre a academia e o controle externo. Teve como proposta final a elaboração de um trabalho factual relacionando às necessidades de sua comunidade e às políticas públicas propondo soluções possíveis, inovadoras e viáveis, geradoras de valor público coletivo. Foram apresentados aproximadamente 700 trabalhos e selecionados os cinquenta melhores textos, os quais foram objeto de análise no curso (VUOLO; MACIEL, dos ANJOS, 2017). Neste caso, as ponderações com pessoas de vários municípios e de diferentes realidades, viabilizando um diálogo democrático e a transferência de experiências, de conhecimento e de informações, só foram possíveis com a utilização do ambiente virtual de aprendizagem e a incorporação das tecnologias digitais.

Ao final, é possível entender o poder da união de diferentes conhecimentos e informações públicas que, mediados pela tecnologia do ambiente virtual de aprendizagem permitem, sob o ponto de vista educacional, o acesso e a atuação de diferentes sujeitos e a construção de novos conceitos e ideias que impregnam esses ambientes (VALENTE, 2002).

\section{Cenário Político, Social e Legal}

Para melhor compreensão dos fatos, será apresentado o cenário político, social e legal desta conjuntura de fatos e ações. Pode-se dizer que o ponto de partida para a realização dessas ações ocorreu a partir da promulgação da Constituição Federal de 1988 por meio da qual foram institucionalizados uma série de espaços para a participação da sociedade civil na gestão pública nos três níveis governamentais (municipal, estadual e federal).

Peruzzotti e Smulovitz (2002) que estudam a participação cidadã associada à vigilância dos recursos públicos, defendem que há uma nova forma de politização que está se desenvolvendo nas novas democracias e que tem por objetivo primordial fortalecer e aperfeiçoar o funcionamento dos mecanismos de controle e supervisão das instituições representativas, e que os cidadãos afetados pelas ações públicas, no exercício de sua cidadania, devem pedir contas aos gestores sobre suas ações.

A interlocução entre o controle externo e o controle social é recepcionada na consolidação dos direitos civis, sociais e políticos que convergem para a enumeração das oportunidades e dos instrumentos de democratização, transparência e inserção da voz do cidadão nos processos decisórios da gestão pública, principalmente no viés da orçamentação das políticas públicas.

A interação crescente entre os controles estatal (controle externo) e não estatal (controle social) foi sendo inserida na legislação brasileira, como na Lei de Responsabilidade Fiscal, a Lei Complementar n. ${ }^{\circ}$ 101/00 (LRF), que determinou a necessidade de equilíbrio das finanças públicas, introduziu a garantia da transparência e da participação da sociedade no processo de elaboração das políticas públicas (BRASIL, 2000). A necessidade dessa aproximação ganhou reforço com a edição da Lei de Acesso à Informação - Lei 12.527/11, que tornou a transparência uma ação obrigatória para toda a administração pública bem como a implementação nos sítios oficiais eletrônicos, de espaços contendo todas as informações públicas de interesse coletivo ou geral produzidas ou custodiadas pelo Estado (BRASIL, 2011). Esta arquitetura legal implicou em vários desafios para as instituições públicas e a sociedade. Para as primeiras há o dever de implementar mecanismos formais de participação e promover o 
empoderamento social das suas informações e decisões e, para a sociedade, a incumbência de exercer seu papel de principal interessada nos resultados do Estado, apta a demandar dele novas estruturas de governança que possibilitem o desempenho de funções de proposição, avaliação, direcionamento e monitoramento das políticas públicas. Segundo Torres (2008, p.180), a comunidade poderá invocar a proteção ao Tribunal de Contas para o combate à corrupção, para o controle dos incentivos fiscais e para promover a fiscalização sobre as entidades financeiras privadas.

De acordo com o Relatório de Desenvolvimento Humano (RDH) elaborado pelas Nações Unidas, em 2015, o Brasil figura entre as sociedades mais desiguais do mundo, aparecendo como o $10^{\circ}$ no ranking, e suas políticas públicas precisam ser formuladas e executadas para amenizar esta realidade e gerar melhoria na qualidade de vida da população. É exatamente em função desse cenário que ocorreu a interface entre os cidadãos, o órgão de controle externo - o TCE-MT e a universidade - a UFMT.

\section{Controle social e controle externo: a integração e os Tribunais de Contas}

Em se tratando de controle, é válido ressaltar, a fim de se fundamentar a discussão que se pretende, que esta ação deve acontecer desde o planejamento, execução e fiscalização constante da destinação do dinheiro público. Acerca das prerrogativas constitucionais relacionadas ao controle dos recursos públicos, é importante ressaltar aqui o teor da Emenda Constitucional $\mathrm{n}^{\circ}$ 19/98, que alterou o parágrafo $3^{\circ}$ do Art. 37 da Constituição Federal. Ao tratar das formas de participação do cidadão/usuário na administração pública, a Emenda Constitucional no 19/98 estabeleceu uma perspectiva de controle direto dos recursos públicos nos seguintes termos:

$\S 3^{\circ}$ - A lei disciplinará as formas de participação do usuário na administração pública direta e indireta, regulando especialmente: I as reclamações relativas à prestação dos serviços públicos em geral, asseguradas a manutenção de serviços de atendimento ao usuário e a avaliação periódica, externa e interna, da qualidade dos serviços; II - o acesso dos usuários a registros administrativos e a informações sobre atos de governo, observado o disposto no art. $5^{\circ}$, X e XXXIII; III - a disciplina da representação contra o exercício negligente ou abusivo de cargo, emprego ou função na administração pública.

Assim, a Carta Magna brasileira possibilita ao cidadão exercer uma forma de democracia direta (de soberania popular). A materialização desse exercício caracterizase por ser o controle social. Os meios de controle social teriam como base de sustentação a fiscalização das ações públicas. Portanto, o controle social poderia ocorrer por monitoramento legal ou iniciativa individual ou coletiva de grupo social.

De acordo com Faccioni (2006), o Tribunal de Contas da União tem por primazia a promoção de uma ligação entre os indivíduos e a administração, na medida em que contribui para a efetivação da democracia participativa, o exercício da cidadania (enquanto princípio fundamental) e a interface entre o controle externo e o controle social. Nessa esteira, evidencia-se o Art. 74, $\S 2^{\circ}$ da Constituição Federal de 1988, que atribuiu ao Tribunal de Contas da União a competência para apreciação de irregularidades ou ilegalidades na Administração Pública, a partir da ação do cidadão e algumas entidades, a saber, qualquer cidadão, partido político, associação ou sindicato é parte legítima para, na forma da lei, denunciar irregularidades ou ilegalidades perante o Tribunal de Contas da União. 
Os Tribunais de Contas, enquanto fiscalizadores da gestão, devem mensurar os resultados obtidos pelo governo e a qualidade das políticas públicas, buscar que sua atuação tenha ressonância na sociedade e disponibilizar informações que precisam ser entendidas e consumidas pelo cidadão. Do lado das instituições, pode haver o receio de se relacionar com a sociedade, como assevera Fernandes (2008); da perspectiva da sociedade, pode haver a "letargia social" que precisa ser abandonada para "alavancar a expressão de uma consciência que se revela imanente no corpo social, aguardando motivação"(p.50).

\section{O Curso de Extensão: "Cidadania e Controle Social”}

O curso foi ofertado inicialmente em 2013 com apenas 200 vagas. Em 2017 foram ofertadas 2.000 vagas do curso de EAD - "Cidadania e Controle Social", divididas em 40 turmas, acompanhadas por 40 tutores e supervisionadas por quatro técnicos do TCEMT, certificado pela UFMT como curso de extensão. O presente estudo abordará apenas a versão do curso desenvolvia em 2017.

O objetivo fundamental do curso foi capacitar os conselheiros dos Conselhos Municipais e Estaduais, estudantes e membros da sociedade para o exercício do controle social, fomentando sua interface com o controle interno e externo. Os objetivos específicos do curso foram a. compreender controle social como pressuposto da democracia; b. contribuir para o fortalecimento dos Conselhos Municipais, Estaduais e Escolares como instâncias efetivas de controle social, levando-os a propor formas de intervenção em sua realidade local; c. conhecer e caracterizar as três formas de controle da Gestão Pública (interno, externo e social), identificando os atores responsáveis; d. Conhecer o TCE-MT, os projetos e programas desenvolvidos relacionados ao estímulo ao controle social como o PDI, os sistemas de informação e transparência e as ações de controle social; e. Conhecer o site do TCE-MT e as decisões do controle externo relacionadas às políticas públicas de sua cidade; f. Conhecer o ciclo orçamentário e as formas de participação do cidadão no processo de orçamentação pública.

Contando com um aparato de fórum e uma estratificação em coordenadores, tutores e alunos, o acompanhamento passou a ser feito pontualmente através de reuniões, relatórios e outras formas. O curso contemplou 100 horas dedicadas à discussão sobre a importância e as diferentes formas de acompanhamento e controle social e externo, com vistas à definição e vivência da cidadania. A aprovação ficou condicionada à elaboração de um trabalho conclusivo substancial pelos cursistas. As produções acadêmicas oriundas do curso representam o indicador de maior representatividade de importância do curso ofertado.

\subsection{Sobre o curso}

Desta vez, mais de 1.000 alunos concluíram o curso, o que representou uma taxa de evasão de 50\%, sendo que os 679 alunos foram aprovados e redigiram um trabalho conclusivo substancial, o que lhes viabilizou a certificação pela UFMT (MEC). Esta produção acadêmica veio a ser o indicador de maior representatividade da nova fase do curso de extensão.

Entre as inovações executadas na versão do curso por ora apresentado, algumas foram muito positivas como: a) a abertura à população em geral, desde que se possuísse pelo menos ensino fundamental completo; por isso, as turmas eram compostas por 
cursistas de perfis e conhecimentos heterogêneos, residentes na capital, no interior de Mato Grosso e até em outros estados da Federação; b) o novo layout do AVA e o design gráfico dos módulos com ícones de fácil identificação prenderam a atenção do cursista no menu "Texto Didático", bem como o "Guia de Estudo", o que favoreceu um melhor entendimento das regras gerais de funcionamento de toda estrutura do curso; o acompanhamento das interações realizadas no AVA possibilitaram avaliar a quantidade de acesso e a participação crítica/reflexiva no ambiente; c) a oportunidade para os cursistas assistirem ao vivo, via Facebook, ao evento Consciência Cidadã e interagirem simultaneamente, comentando ou fazendo perguntas aos participantes desse evento de estímulo ao controle social foi bem avaliada; d) a inserção dos menus "Saiba Mais", com bibliográficas suplementares, e do "Vídeos", com temas correlatos aos debatidos no curso, propiciou a compreensão do assunto através de outra linguagem, bem como estimulou a ampliação dos horizontes dos cursistas; e) novas funcionalidades inseridas no ambiente, entre as quais destacou-se a inserção de alguns "menus" para auxiliar os cursistas no desenvolvimento do curso, o "Suporte Técnico", os "Tutoriais" e o "FAQ", destinados a sanar dúvidas dos cursistas por meio da compilação das perguntas mais recorrentes e/ou dúvidas possíveis acerca do curso; f) a "Sala do Tutor" integrou os coordenadores, supervisor, tutores, suporte técnico da UFMT/Uniselva e coordenação do TCE, e no "Fórum Geral do Aluno" as dúvidas dos cursistas sobre os assuntos teóricos e exercícios do curso foram tiradas com mais celeridade.

Segundo Mill (2010), nos últimos anos, a Educação a Distância brasileira passou por uma vertiginosa expansão e por um enorme reconhecimento nunca percebido na modalidade. Nesse contexto de expansão da $\mathrm{EaD}$, insere-se o curso apresentado no presente trabalho. Os números mostram que o TCE-MT, em parceria com a UFMT, atendeu 97\% dos 141 municípios do Estado de Mato Grosso. Assim, tivemos cursistas de 137 municípios participando efetivamente do Curso. Além desses, foram atendidos 26 municípios de outros estados. Salienta-se que o maior número de cursistas inscritos concentrou-se nos municípios mais populosos, como Cuiabá e Várzea Grande. Entre os inscritos, verificam-se cursistas com nível fundamental de escolaridade, bem como doutores que desempenham suas atividades como defensores públicos, fiscais de tributos estaduais, serviços gerais, do lar, entre outros.

Ao final do Curso, os alunos apresentaram o trabalho final com reflexões importantes sobre o percurso realizado durante os estudos dos respectivos módulos. Ao todo, tivemos aproximadamente 700 (setecentos) trabalhos. Desses, 50 foram previamente selecionados, observando-se a estrutura quanto à formatação do trabalho, problematização, coerência e coesão textual (VUOLO; MACIEL, dos ANJOS, 2017). Neste quadro, pode-se identificar que os 50 trabalhos escolhidos são provenientes de 27 municípios do estado de Mato Grosso, sendo que, destes, $38 \%$ são da capital matogrossense (19 trabalhos). A análise realizada sobre os artigos selecionados evidencia que as temáticas abordadas foram extremamente variadas. Parece haver uma preocupação maior com as políticas públicas voltadas à preservação ambiental e à educação, esporte e lazer. Salientamos que os trabalhos analisados envolvendo políticas públicas educacionais enfatizavam alunos da educação básica. A preocupação com a atuação junto aos Conselhos Municipais também aparece de forma significativa.

No Figura 1, há as temáticas abordadas para a construção dos trabalhos finais do Curso de Cidadania e Controle Social. São pesquisas voltadas para as Políticas Públicas dos municípios nos quais estavam inseridos os cinquenta trabalhos selecionados. 


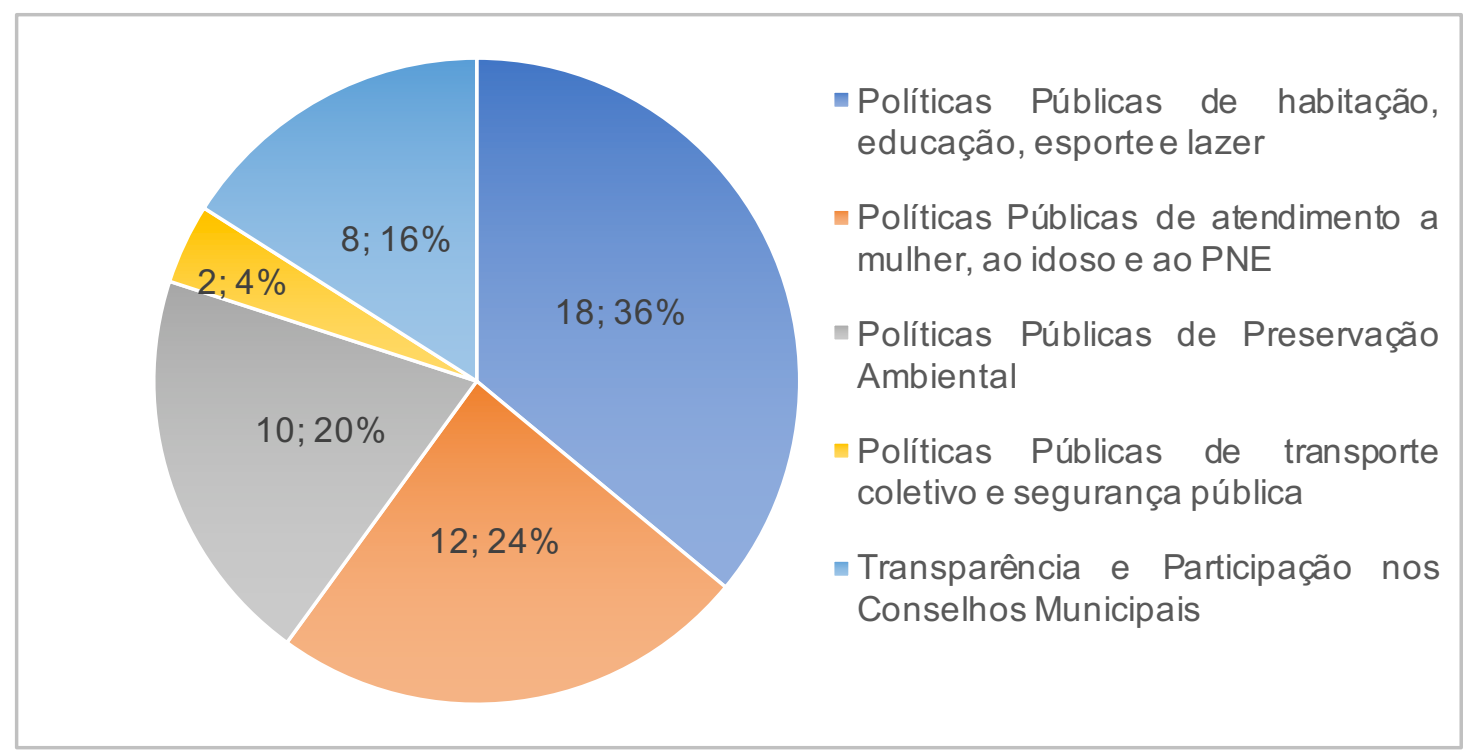

Figura 1. Temáticas abordadas nos trabalhos dos participantes do curso

$\mathrm{Na}$ representação gráfica, é possível perceber a preocupação com diversas temáticas quando se fala em Políticas Públicas. A maior preocupação trazida nos textos reflexivos refere-se às políticas de habitação, educação, esporte e lazer. Viu-se que $35 \%$ das pesquisas selecionadas demonstram a necessidade da garantia das condições mínimas de sobrevivência quando se fala em cidadania. Talvez seja importante enfatizar que ter essa consciência perpassa todo um processo de sensibilização, de empoderamento das questões sociais em busca da garantia dos direitos e consequentemente do exercício da cidadania plena.

Outra preocupação bastante evidente nos textos refere-se às políticas públicas de atendimento à mulher, ao idoso e ao portador de necessidades especiais. Identifica-se $25 \%$ dos trabalhos envolvidos com essa temática. As discussões realizadas ao longo do curso possibilitaram uma sensibilização com as minorias. É importante salientar que a temática saúde apareceu significativamente nas reflexões dos trabalhos voltados à mulher e ao idoso, bem como reflexões pertinentes sobre a acessibilidade dos que possuem alguma necessidade especial. Os trabalhos mostram como o atendimento à saúde tem sido precário especialmente quando se reporta à mulher e ao idoso.

Nos $20 \%$ dos trabalhos que tratam de políticas públicas voltadas à preservação ambiental, percebe-se uma grande preocupação com a destinação dos resíduos sólidos. Os trabalhos apontam que ainda não há efetivamente políticas públicas eficazes que consigam resolver o problema da destinação dos resíduos sólidos e de saneamento básico. Ainda nesse contexto das temáticas abordadas, temos $16 \%$ dos trabalhos preocupados com a Transparência e fiscalização dos conselhos Municipais. Os dados coletados apontam que a população ainda não tem consciência da importância da participação efetiva nos diversos conselhos existentes.

Percebe-se que, nesse contexto, a transparência ganha expressão como um tema estratégico da agenda pública do país e se consagra como instrumento fundamental para se trabalhar com a complexa relação entre os cidadãos e seus agentes. A utilização efetiva de ferramentas e tecnologias de informação, especialmente da internet, torna-se importante aliada e apresenta-se como processo democrático que integra uma rede 
capaz de dar visibilidade e transparência às decisões e aos resultados alcançados, através da criação de condições favoráveis de acesso aos dados públicos. Os outros $4 \%$ dos trabalhos preocuparam-se com o transporte e a segurança pública. A preocupação maior esteve voltada para a qualidade do transporte público e a segurança nos pontos de ônibus. Além da necessidade do fortalecimento de políticas para proteção do usuário do transporte público, as pesquisas mostram a necessidade de priorizar os deslocamentos coletivos nos espaços urbanos para diminuir o tempo de viagem da população.

Ainda, cabe reforçar que os números totalizados no projeto são expressivos: 2.567 pessoas foram estimuladas a exercerem o controle social por meio desta capacitação, havendo representantes em $100 \%$ dos municípios adesos ao PDI, além de 22 cursistas de outros estados da federação. Além disso, dos 676 cursistas que concluíram o curso, ou seja, que obtiveram nota igual a 7,0 ou superior, $41 \%$ são membros de Conselhos, 54\% deles ligados aos Conselhos da Educação, tanto que houve 113 professores concluintes. Dos 141 municípios de Mato Grosso, 122 possuíam munícipes inscritos e em 89 deles houve concluintes.

\section{Considerações finais}

As inovações, de forma geral, contribuíram em muito para o sucesso desta versão remodelada desta iniciativa de educação para transparência, sendo que o trabalho da Escola de Contas merece ser destacado na medida em que não envidou esforços para realizar com a habitual excelência este curso que não se encaixava nos padrões dos cursos ofertados pelo ensino à distância.

Nesse sentido, o curso de Cidadania e Controle Social trouxe importantes reflexões tais quais: o que é ser cidadão? Quem sou eu na sociedade? De que forma posso contribuir para melhorar as condições sociais do meu país e exercer efetivamente a cidadania? Como realizar uma denúncia e acompanhar as ações tomadas na resolução dos problemas? Entende-se que a conscientização é o ponto de partida para que o cidadão possa repensar e transformar sua práxis. Nesse sentido, salienta-se a importância do Curso de Cidadania e Controle Social na preparação dos conselheiros que fazem parte dos conselhos e do cidadão comum que atua, interage e pode intervir na sociedade de forma a garantir seus direitos e estar consciente de seus deveres. As práticas realizadas durante o desenvolvimento do Curso contribuíram significativamente para que essas reflexões e tomadas de decisões fossem pensadas de forma consciente e transparente, pautadas nas legislações existentes e visando sempre o bem comum.

Espera-se que, bem informados, os membros da sociedade deixem de ser administrados e tornem-se cidadãos ativos e influam de fato nos atos do poder tomados em seu nome. A integração ativa e participativa dos cidadãos, influenciando e decidindo na administração, é um dos pressupostos para a incorporação da sociedade civil como um dos intérpretes da Constituição (MANGIA, 2014).

O histórico de inovação e superação construído por todos os atores envolvidos na construção deste projeto educacional e profundamente social reflete, em sua íntegra, a mesma linha inovativa e progressiva do próprio Tribunal de Contas de Mato Grosso que, ao longo de seu amplo desenvolvimento institucional alcançado ao longo da última década, soube criar também uma vasta e profícua rede de articulação social. No caso específico deste curso de extensão, foi a rede criada entre TCE-MT, Secretaria de Articulação Institucional e Desenvolvimento da Cidadania - SAI, Escola Superior de 
Contas, UFMT/Uniselva e os conselhos de políticas públicas que permitiu tamanho índice de protagonismo, de onde surge a certeza de que o caminho para uma democracia real e participativa passa, via de regra, pelo exercício do Controle Social.

Os dados informam que no processo de amadurecimento da democracia participativa, tanto a sociedade quanto o Estado são chamados a se modificarem, a construírem aliança em torno de pautas coletivas, a praticarem mediações sociais e políticas visando o atendimento de pautas populares e a caminharem na direção da estruturação de esferas públicas autônomas e democráticas no campo das decisões políticas (RAICHELiS, 2000).

Sob o ponto de vista de empoderamento social, a diversidade de formação dos cursistas nos permite dizer que diferentes espaços de discussão plural foram atingidos de diferentes modos, sendo, inclusive, recomendado um estudo focal para identificar tais impactos e medir a efetividade da voz perante a gestão pública. Em um país com dimensões como as do Brasil, com cultura de má gestão dos recursos, ainda que a politização da sociedade esteja aumentando, somente a atuação dos órgãos de controle é insuficiente para combater as irregularidades cometidas, sendo cada vez mais urgente ouvir a sociedade, estimulá-la ao exercício do controle social e incentivar a educação para a transparência. Esperamos que esta experiência fortaleça o diálogo democrático e republicano, ainda pouco efetivado, mas possível e necessário, que pretende se lançar daqui para novos horizontes

\section{Referências}

ANJOS, A. M. dos. Tecnologias da informação e da comunicação, aprendizado eletrônico e ambientes virtuais de aprendizagem. In Maciel, C. Educação a distância: Ambientes virtuais de aprendizagem. Cuiabá: EdUFMT, 2014, p. 11-57.

BRASIL. XXIII ASSEMBLEIA GERAL DA OLACEFS. Revista do Tribunal de Contas da União. Brasil, ano 46, n. 129, p. 17, jan/abr., 2014. Disponível em <http://revista.tcu.gov.br/ojs/index.php/RTCU/article/download/18/16>. Acesso em: 05 jun.2017.

BRASIL. Lei $\mathrm{n}^{\mathrm{o}}$ 12.527, de 18 de novembro de 2011. Regula o acesso a informações previsto no inciso XXXIII do art. 5o, no inciso II do $\S 30$ do art. 37 e no $§ 20$ do art. 216 da Constituição Federal; altera a Lei no 8.112, de 11 de dezembro de 1990; revoga a Lei no 11.111, de 5 de maio de 2005, e dispositivos da Lei no 8.159, de 8 de janeiro de 1991; e dá outras providências. http://www.planalto.gov.br/ccivil_03/_ato2011-2014/2011/lei/112527.htm. Acesso em 10 jan 2018.

BRASIL. Emenda Constitucional n ${ }^{\circ} 19$, de 04 de junho de 1998. Modifica o regime e dispõe sobre princípios e normas da Administração Pública, servidores e agentes políticos, controle de despesas e finanças públicas e custeio de atividades a cargo do Distrito Federal, e dá outras providências. Disponível em http://www.planalto.gov.br/ccivil_03/Constituicao/Emendas/Emc/emc19.htm. Acesso em 10 jan 2018.

BRASIL. Constituição da República Federativa do Brasil de 1988. Disponível em http://www.planalto.gov.br/ccivil_03/constituicao/constituicao.htm. Acesso em 10 jan 2018.

BRASIL. Lei Complementar $n^{\circ} 101$, de 4 de maio de 2000. Estabelece normas de finanças públicas voltadas para a responsabilidade na gestão fiscal e dá outras 
providências. Disponível em: http://www.planalto.gov.br/ccivil_03/ Leis/LCP/Lcp101.htm. Acesso em 10 jan de 2018.

DE OLIVEIRA, L. K. B.; MACIEL, C.. Transparência das Contas Públicas e Controle Social via Portal do Cidadão-um estudo de caso. Anais do WTRANS13 - Workshop de Transparência em Sistemas, Brasília, Brasil, Setembro 29, 2013.

FACCIONI, V. J. A Sociedade e o Controle Externo. In: I Fórum do PROMOEX: Formação da Rede de Informação e Portal do Controle Externo. TCE-MG. Belo Horizonte, 2006.

GIRATA, N. N. H.; MACIEL, C.. eGov website evolution study within strategic planning. In: Proceedings of the 15th Annual International Conference on Digital Government Research. ACM, 2014. p. 69-78.

KUHN, A. P.; ROUILLER, C. O.; MACIEL, C.. Um olhar sobre os trabalhos dos participantes do curso a distância de cidadania e controle social. In VUOLO, Cassyra L;MACIEL, Cristiano; ANJOS, Alexandre dos. Educação a Distância: (In)formação em Cidadania e Controle Social. Cuiabá-MT: EdUFMT, 2017, p.173-188.

MACIEL, C., GARCIA, A. C. B.. Modeling of a Democratic Citizenship Community to Facilitate the Consultative and Deliberative Process in the Web. In ICEIS, 2007, pp. 387-394.

MACIEL, C., CAPPELLI, C., SLAVIERO, C., GARCIA, A. C. B.. Technologies for popular participation: a research agenda. In: Proceedings of the 17th International Digital Government Research Conference on Digital Government Research. ACM, 2016. p. 202-211.

MANGIA, C. de C.. Participação popular, cidadania e Estado Democrático de Direito. Revista Jus Navigandi. Teresina, ano 19, n. 4094, 16 set. 2014. Disponível em: <https://jus.com.br/artigos/29663>. Acesso em: 26 dez. 2016.

MILL, D.. Das inovações tecnológicas às inovações pedagógicas: considerações sobre o uso das tecnologias na educação a distância. In: MILL, D. PIMENTEL, N. Educação a Distância: desafios contemporâneos. São Carlos:EdUFSCar, 2010.

MONSALVE, E.; WERNECK, V.; LEITE, J. C. S. P. Incorporando transparência na pedagogia através do uso de jogos para ensino. Anais do WTRANS13 - Workshop de Transparência em Sistemas, Brasília, Brasil, Setembro 29, 2013.

NERLING, M.. Preparar para o exercício da cidadania, através do controle social, na Gestão de Políticas Públicas. IN: VUOLO, C. L; MACIEL, C.; ANJOS, A. M. dos. Educação a Distância: (In)formação em Cidadania e Controle Social. Cuiabá-MT: EdUFMT, 2017, p. 17-67

PERUZZOTTI, E.; SMULOVITZ, C. Controlando la Política: ciudadanos y médio sem las nuevas democracias. Buenos Aires: Editorial Temas, 2002, p. 23-52.

RAICHELIS, R.. Desafios da gestão democrática das políticas sociais. Módulo 03. Capacitação em Serviço Social e Política Social. Programa de Capacitação Continuada para Assistentes Sociais. Brasília, CFESS, ABEPSS, CEAD/NED-UNB, 2000.

TORRES, R. L.. Curso de Direito Financeiro e Tributário. 7. ed. Rio de Janeiro: Renovar, 2008.

VALENTE, J. A. A espiral da aprendizagem e as tecnologias da informação e comunicação: repensando conceitos. In: Joly, M. C. (Ed) Tecnologia no Ensino: implicações para a aprendizagem. São Paulo: casa do psicólogo, 2002, p. 15-37.

VUOLO, C. L; MACIEL, C.; ANJOS, A. M. dos. Educação a Distância: (In)formação em Cidadania e Controle Social. Cuiabá-MT: EdUFMT, 2017. 